\title{
OBSEG IN KARAKTER SLOVENSKE VOJSKE
}

\section{SLOVENIAN ARMED FORCES SIZE AND CHARACTER}

Povzetek Besedilo obravnava vprašanji o obsegu in karakterju Slovenske vojske (SV). Že nekaj časa se namreč pojavljajo zamisli o nadaljnjem zmanjševanju stalne sestave SV, ki zaradi omejenih finančnih sredstev dobivajo še dodaten zagon. V članku je kratek zgodovinski pregled obsega oboroženih formacij slovenskega naroda v luči izpolnjevanja nalog SV, kot so zapisane v Zakonu o obrambi (ZoObr). Obravnavam tudi karakter SV in osrednjega vira njene bojne moči, in sicer pehote. Vojske v zavezništvu in širše poznajo več tipov pehote, kar je treba upoštevati, ko razmišljamo o tem, kakšno pehoto bomo v SV imeli. Seveda se zavedamo finančnih omejitev, ki jim je SV izpostavljena, zato v sklepnem delu predstavljamo nekaj predlogov, kako uresničiti predlagana obseg in značaj SV, ki so namenjeni dodatni razpravi in bi bili potrebni bolj poglobljene analize.

Ključne Obseg oboroženih sil, Slovenska vojska, Nato, pehota, stalna sestava, vojaška besede strateška rezerva.

Abstract The text deals with the questions of the size and character of Slovenian Armed Forces (SAF). For some time now one has been able to track ideas of decreasing the size of the SAF active component, which have additionally gained momentum due to the limited defence resources. The texts looks at the size of Slovenian armed structures from the historic perspective in the light of the tasks set before SAF by the Defence Act. The article also deals with the SAF's character and the source of its fighting power - the infantry. Allied and other armies list several types of infantry, the fact which should be taken into consideration when deliberating on the type of infantry in the SAF. Of course, we are aware of the financial restrictions imposed on the SAF; therefore the conclusion includes some suggestions on how to achieve the proposed size and character of the SAF. The suggestions, however, are intended more as a base for a discussion and would have to be further analysed. 


\section{Key words Size of armed forces, Slovenian Armed Forces, NATO, infantry, active component, military strategic reserve.}

Uvod Teritorialna obramba Republike Slovenije (v nadaljevanju TORS) je na vrhuncu moči obsegala vojno sestavo z več kot 80.000 pripadniki. V resnici jih nikoli ni bilo toliko tudi mobiliziranih, toda njena vojna formacija je omogočala tolikšen obseg. Po končani osamosvojitveni vojni in pozneje, s koncem oboroženih spopadov na ozemlju nekdanje Jugoslavije, se je obseg TORS in pozneje SV postopoma spreminjal. Z vojne sestave 54.000 pripadnikov leta 1994 do največ 73.000 leta 2001 in 39.000 v letih 2002 in 2003 in 16.000 leta 2004 (Grizold, 2005, str. 125, 127) do zdaj dovoljenih 10.000. Ob tem sta SV in prej TORS večino časa ohranila karakter lahke pehotne vojske $\mathrm{z}$ majhno manevrsko in večjo prostorsko strukturo. ${ }^{1}$ Že nekaj časa se pojavljajo tudi bolj ali manj uradne zamisli o tem, da bi bilo treba obseg in strukturo SV še zmanjšati. Ob tem se večinoma omenja številka okoli 5000 pripadnikov. Hkrati znotraj SV in tudi v zainteresirani javnosti potekajo neuradne razprave o tem, kakšen naj bo sploh karakter SV.

Obseg in karakter SV se ugotavljata z nalogami, ki so zaupane SV, z grožnjami, ki jim je RS izpostavljena, in z njeno vključenostjo v zavezništvo. Upoštevati pa moramo tudi zgodovinske izkušnje oziroma obseg in karakter oboroženih sil slovenskega naroda od začetka 19. stol. naprej. SV je in bo predvsem kopenska vojska s pehoto kot njenim osrednjim rodom, ki je osrednji vir njene bojne moči. Drugi rodovi in službe so v funkciji podpore ali zagotovitve delovanja pehote v omejenem obsegu, delujejo pa lahko tudi samostojno. V okviru pehote kot osrednjega rodu in izvora bojne in nebojne moči SV se zastavlja vprašanje, kakšno pehoto sploh potrebujemo. Ni namreč vsak tip pehote primeren za naloge in vire, ki jih ima SV.

\section{NALOGE SLOVENSKE VOJSKE IN NATA}

Naloge SV izhajajo iz ZoObr (37. člen) in so:

- izvajanje vojaškega izobraževanja in usposabljanja za oboroženi boj in druge oblike vojaške obrambe;

- zagotavljanje potrebne ali zahtevane pripravljenosti;

- ob napadu na državo izvajanje vojaške obrambe;

- ob naravnih in drugih nesrečah skladno s svojo organizacijo in opremljenostjo sodelovanje pri zaščiti in reševanju (ZiR);

- izvrševanje obveznosti, ki jih je država sprejela v mednarodnih organizacijah in z mednarodnimi pogodbami.

\footnotetext{
$V$ devetdesetih je veljala delitev na manevrske in prostorske sile, nato se je leta 2001 delitev spremenila $v$ sile za posredovanje, glavne sile in dopolnilne sile, da bi se leta 2004 dokončno poenotila z zavezništvom. Zdaj delimo sile SV glede na vlogo v sistemu bojevanja na sile za bojevanje, sile za bojno podporo, sile za zagotovitev bojnega delovanja in sile za podporo PINK, in sicer glede na sposobnost premeščanja (premestljive in nepremestljive sile) in glede na stopnjo pripravljenosti (sile v visoki stopnji pripravljenosti, sile v nizki stopnji pripravljenosti in sile z daljšim časom vzpostavitve pripravljenosti) (Grizold, 2005, str. 134, 135, 136).
} 
Naloge iz ZoObr so jasne. SV mora izvajati vojaško obrambo ob napadu, ob večjih nesrečah sodeluje v ZiR in izpolnjuje mednarodne obveznosti, ki jih vojska lahko izpolnjuje. Zato mora izvajati usposabljanje in zagotavljati ustrezno pripravljenost. Poslanstvo SV je z različnimi strateškimi dokumenti različno opredeljeno.

Resolucija o splošnem dolgoročnem programu razvoja in opremljanja SV do leta 2025 (ReSDPRO) opredeljuje kot namen SV, da »z vojaškimi zmogljivostmi prispeva $\mathrm{k}$ uresničevanju interesov in nacionalnovarnostnih ciljev Republike Slovenije« (DZRS, 2010, str. 10), kot poslanstvo SV pa ReSDPRO SV 2025 v bistvu povzame naloge iz ZoObr.

Obrambna strategija RS kot poslanstvo SV navaja, da »z vojaškimi zmogljivostmi zagotavlja vojaško moč RS, kot najmočnejši in skrajni instrument države za uveljavljanje oz. uresničevanje njenih nacionalnih interesov in nacionalnovarnostnih ciljev.« (Vlada RS, 2012, str. 9).

Vojaška doktrina iz leta 2006 kot poslanstvo SV navaja: »Poslanstvo Slovenske vojske je v sodelovanju z zavezniki odvrniti vojaško agresijo na Republiko Slovenijo in prispevati $\mathrm{k}$ mednarodnemu miru in stabilnosti v mejah in zunaj meja zavezništva. $\mathrm{V}$ primeru vojaške agresije Slovenska vojska samostojno in $\mathrm{V}$ sodelovanju $\mathrm{z}$ zavezniki izvaja vojaško obrambo Republike Slovenije s ciljem pregona sovražnika in vzpostavitve suverenosti na celotnem ozemlju države.« (Furlan, 2006, str. 24).

Na podlagi omenjenega lahko ugotovimo, da strateški dokumenti poslanstva SV ne opredeljujejo enotno, kar ima lahko negativne posledice. Poslanstvo, kot je zapisano v ReSDPRO SV 2025 in Obrambni strategiji, se nanaša na tako imenovano veliko strategijo $^{2}$ države in obravnava njeno vlogo $\mathrm{v}$ odnosu do nacionalnovarnostnih interesov oziroma ciljev. Poslanstvo, povzeto iz vojaške doktrine, pa bolj konkretizira način delovanja SV pri sledenju tem ciljem in pomeni boljši okvir za razpravo o karakterju in obsegu SV.

Na podlagi strateških dokumentov torej lahko sklenemo, da je obrambna strategija RS odvračalna in da se za zagotavljanje lastne varnosti večinoma zanaša na zavezništvo. Pri tem se lahko hitro znajde v pasti prevelikega prelaganja odgovornosti za lastno varnost na druge članice zavezništva, zato je treba dobro razumeti, kakšno in kolikšno varnost daje zavezništvo. Menim, da je v tem pogledu ključno poznavanje in razumevanje 3. in 5. člena Severnoatlantske pogodbe.

Peti člen pogodbe pravi: »Pogodbenice soglašajo, da se oboroženi napad na eno ali več pogodbenic v Evropi ali Severni Ameriki šteje za napad na vse pogodbenice, in zato soglašajo, da bo v primeru takega oboroženega napada vsaka od njih ob uresničevanju pravice do individualne ali kolektivne samoobrambe, ki jo priznava 51. člen Ustanovne listine Združenih narodov, pomagala tako napadeni pogodbenici ali pogodbenicam $s$ takojšnjim individualnim in $z$ drugimi pogodbenicami

2 Pojem uporablja Barry Posen v svoji knjigi in se nanaša na nacionalnovarnostne strategije držav. 
dogovorjenim ukrepanjem, ki se ji zdi potrebno, vključno z uporabo oborožene sile, da se ponovno vzpostavi in ohranja varnost severnoatlantskega območja. ${ }^{3}$

Peti člen sicer res govori o tem, da je napad na eno članico zavezništva napad na vse, toda hkrati vsaki posamezni državi omogoča, da se na njej lasten način odzove na ta napad. Oborožena sila je le eden izmed načinov, na katerega se lahko odzovejo, kar pomeni, da napad na RS ne bi nujno pomenil pomoč zavezništva v obliki, kakršno bi pričakovali. Zavezništvo nima lastnih oboroženih sil, temveč gre za sile, ki jih prispevajo v skupna poveljstva posamezne članice. Zavezništvo nas dela varnejše le v povezavi z globalnimi grožnjami, ki bi ogrožale tako Slovenijo kot večino zaveznic oziroma vsaj najmočnejše države zaveznice. Ob lokalni grožnji pa je zanašanje na zavezništvo vprašljivo.

Tretji člen Severnoatlantske pogodbe pravi: »Za učinkovitejše doseganje ciljev te pogodbe bodo pogodbenice $\mathrm{z}$ nenehno in učinkovito samopomočjo ter vzajemno pomočjo vsaka zase in skupaj vzdrževale in razvijale svojo individualno in kolektivno sposobnost upreti se oboroženemu napadu. $\ll^{4}$

Tretji člen pogodbe jasno postavlja zahtevo, da vsaka država članica sama razvija lastne zmogljivosti za obrambo pred oboroženim napadom. Zato se ne moremo strinjati z dr. Grizoldom, ki trdi, da »delitve vojaških zmogljivosti na nacionalnoobrambne potrebe in na tiste, ki so na voljo Natu, skoraj ni več«. (Grizold, 2005, str. 187). Članice, med njimi tudi RS, morajo razvijati lastno sposobnost za obrambo pred napadom. ${ }^{5}$ Če članica ne izpolnjuje zahtev tega člena, tudi ne more pričakovati, da bodo druge članice zapolnjevale manke v njenih obrambnih zmogljivostih.

Zavezništvo ima svojo ceno in nobena članica si ne bi smela dovoliti, da zanemarja lastne obrambne zmogljivosti in se pri tem sklicuje na varnost, ki naj bi jo zagotavljal 5. člen pogodbe. Zavezništvo je lahko učinkovito le takrat, če vse zaveznice izpolnjujejo svoje zaveze. Realnost je seveda drugačna in kaže, da politika pogosto prelaga odgovornost za varnost lastne države na druge zaveznice in s tem zanemarja lastne zmogljivosti. Članstvo je lahko izjemno koristno zaradi deljenih zmogljivosti in zmanjševanja stroškov v skupnih projektih. Če se torej RS odpove na primer oklepnim (tankovskim) zmogljivostim, zračni obrambi (ZO), vojaškemu letalstvu in

\footnotetext{
"The Parties agree that an armed attack against one or more of them in Europe or North America shall be considered an attack against them all and consequently they agree that, if such an armed attack occurs, each of them, in exercise of the right of individual or collective self-defence recognised by Article 51 of the Charter of the United Nations, will assist the Party or Parties so attacked by taking forthwith, individually and in concert with the other Parties, such action as it deems necessary including the use of armed force, to restore and maintain the security of the North Atlantic area ... " (http://www.nato.int/ cps/en/natolive/official_texts_17120.htm)

4 "In order more effectively to achieve the objectives of this Treaty, the Parties, separately and jointly, by means of continuous and effective self-help and mutual aid, will maintain and develop their individual and collective capacity to resist armed attack." (http://www.nato.int/cps/en/natolive/ official_texts_17120.htm)

5 Ob najnovejšem valu terorističnih groženj, po napadu na francoski satirični časopis, sta Francija in Belgija na ulice za zagotavljanje varnosti napotili svoje vojake, neodvisno od zavezništva. To so lahko hkrati iste zmogljivosti, ki so na voljo zavezništvu, a dejstvo je, da so nacionalnovarnostne potrebe ločene od zavezništva, kot je dokazal tudi Afganistan, kjer je kljub aktivaciji petega člena trajalo skoraj dve leti, preden se je preostanek zavezništva dejavno vpletel $v$ konflikt.
} 
drugemu, mora imeti jasen načrt, kako bo primanjkljaj teh zmogljivosti nadomestila znotraj zavezništva: ali bo investirala v boljše protioklepne zmogljivosti, skupni sistem zračne obrambe, regionalne zračne sile itn. Slovenija je znotraj zavezništva že našla rešitve za popolnitev primanjkljajev nekaterih zmogljivosti, vsega pa se ne da rešiti skozi zavezništvo. Zagotovo ne z obrambnimi izdatki v višini 1,1% BDP, pri čemer gre za potrebe SV le 0,74 \% BDP. Preostalo gre za druge udeležence obrambnega sistema RS, za civilno zaščito, gasilce idr. (predavanje NGŠSV http:// youtu.be/tEHYGFWO7pQ, od 12.30 do 12.45).

Čeprav v zavezništvu države delijo tveganja, stroške in koristi vojne, pa prinaša zagotavljanje varnosti znotraj zavezništva tudi velike nevarnosti. Države znotraj zavezništev odgovornost za lastno varnost prepuščajo drugim, kar vodi v nerealno zmanjševanje lastnih virov za potrebe varnosti. Druga past zavezništva je pristajanje na vojaško doktrino vodilne nacije, čeprav ta morda ni primerna za majhno državo (Posen, 1984, str. 73). Menimo, da je primer takega zavezništva tudi Nato, pri čemer ZDA, ki imajo izrazito ofenzivno vojaško doktrino, bolj ali manj odkrito vodijo tudi vse druge zaveznice v podobno doktrino. Tako je tudi SV kljub svoji deklarativni zavezanosti odvračalni doktrini strukturno bolj podobna vojski, ki razvija ofenzivno doktrino. ${ }^{6}$

Slovenska politika in javnost se morata jasno zavedati, da smo za varnost lastne države odgovorni predvsem sami in da bo ekstremno varčevanje na obrambnih zmogljivostih pustilo resne posledice.

\section{VARNOSTNE GROŽNJE IN IZZIVI REPUBLIKE SLOVENIJE}

Družba v postmoderni dobi se srečuje s številnimi bolj ali manj verjetnimi grožnjami. Moskos pravi, da »bodo najverjetnejša grožnja državi v postmoderni družbi še dolgo različna revolucionarno/teroristična gibanja« (Moskos v Bebler, 2005, str. 316). Vendar ob tem ne moremo odpisati groženj, ki jim je bila država izpostavljena $\mathrm{v}$ tradicionalni in moderni dobi. ${ }^{7}$ Kot pravi Dandeker, imajo postmoderne oborožene sile »izjemno širok spekter obrambnih nalog in vlog « ter morajo imeti temu primerno strukturo poklicne in rezervne sestave, da bi vse to lahko opravljale (Dandeker v Moskos, 2000, str. 45). Moskos za postmoderne vojske poleg drugih značilnosti izpostavlja tudi spremembo v namenu vojske od zmage v vojni do nalog, ki niso vojaške $\mathrm{v}$ tradicionalnem smislu, in udeležbo vojske na misijah z mednarodno legitimnostjo (Moskos, 2000, str. 2).

\footnotetext{
Ob tem ne smemo zamenjevati ofenzivne doktrine na strateški ravni z ofenzivnostjo na taktični ravni. Tudi vojske, ki na strateški ravni razvijajo defenzivno ali odvračalno doktrino, lahko in celo morajo razviti ofenzivno doktrino na taktični ravni, pri čemer je treba $v$ boju prevzemati iniciativo in posegati v nasprotnikov cikel odločanja. To zagovarja funkcija poveljevanja in kontrole na podlagi poslanstva, kot jo pozna tudi Vojaška doktrina SV, in o kateri sem več pisal v SV junij $2014-16$, št. 2.

Tradicionalne družbe naj bi obstajale do konca druge svetovne vojne, zanje so bile značilne množične nacionalne vojske, moderne družbe pa od konca druge svetovne vojne do konca hladne vojne, zanje so bile značilne vojske s profesionalnim častniškim zborom, zmanjšanim obsegom in naprednim izobraževanjem. Za postmoderne družbe po koncu hladne vojne so značilne vojske, v katerih so meje med civilno in vojaško sfero zabrisane (Moskos v Bebler, 2005, str. 313).
} 
Ne gre za to, katera od groženj je verjetnejša ali pomembnejša. V svetu, ki je tako medsebojno povezan in nestabilen, kot je današnji, je grožnje na dolgi rok nemogoče prioritizirati. Grizold ugotavlja, da je v svetu po hladni vojni grožnjam skupno nekaj elementov (Grizold, 2005, str. 22, 23):

1. povezovanje, prepletanje in medsebojno učinkovanje vojaških in nevojaških groženj varnosti;

2. preraščanje nacionalne varnosti v mednarodno varnost in obratno. Varnost ima danes globalne razsežnosti v prostorskem in vsebinskem smislu. Tako je tudi varnost posamezne države vse bolj domena globalnega mednarodnega sistema;

3. znatno sta se okrepili povezanost in odgovornost med subjekti zagotavljanja varnosti, kot so država, meddržavne in naddržavne organizacije, nevladne organizacije, multinacionalne korporacije, skupine pritiska idr.;

4. instrumenti in mehanizmi za zagotavljanje varnosti so bolj zapleteni in se povezujejo v sistem tako na ravni države kot na ravni mednarodne skupnosti.

Treba je imeti sistem, ki bo zasnovan tako, da se bo lahko ustrezno odzval na vse grožnje in bo finančno vzdržljiv.

Tudi strateški obrambno-varnostni dokumenti RS ugotavljajo podobno in groženj ne prioritizirajo. Ugotavljajo, da je na kratki in srednji rok verjetnost neposredne vojaške grožnje RS majhna, toda ne izključujoča. Hkrati pa asimetrični značaj groženj in njihove hibridne oblike zahtevajo tako nevojaško odzivanje na vojaške grožnje kot vojaško odzivanje na nevojaške grožnje (Obr. strat. RS, 2012, str. 3). Če bi se lahko kaj naučili iz sodobnih kriz in spopadov, je to, da so nepredvidljive. Predvsem pa je nepredvidljiva smer razvoja, ki jo bodo izbrale - bodo ostale lokalne, se bodo razvile v regionalne ali postale celo širše in ne nazadnje globalne. Mednarodni varnostni sistem je preprosto preveč nepredvidljiv in interesi, ki bodo prevladali, niso vnaprej določljivi, da bi lahko z veliko gotovostjo ocenili razvoj dogodkov. To potrjujeta zadnja dva primera krize v Ukrajini, ki je stresla in še vedno stresa celotno Evropo, in uspehi sil Islamske države (ISIL) v Iraku in Siriji.

Če povzamemo dr. Grizolda »sodobno ogrožanje varnosti vključuje poleg konvencionalnih groženj (npr. vojna, oboroževalne tekme, širjenje jedrskega orožja idr.) tudi nevojaške grožnje, ki postajajo vse bolj aktualne, na primer množično nespoštovanje temeljnih človekovih pravic in svoboščin, onesnaževanje okolja in posledično segrevanje ozračja, lakota, nalezljive bolezni, trgovina z drogami in belim blagom, nenadne migracije idr. Omenjene grožnje varnosti so skupaj z mednarodnim terorizmom, orožjem za množično uničevanje ter tako imenovanimi nefunkcionalnimi državami, ki ne ogrožajo le lastnega prebivalstva, temveč destabilizirajo celotno regijo, postali temeljni viri ogrožanja sodobne varnosti. Tovrstne kompleksne grožnje varnosti pa zahtevajo enako kompleksne rešitve.« (Grizold, 2005, str. 24).

Obrambno-varnostni sistem Republike Slovenije in predvsem SV mora tako težiti k čim večji fleksibilnosti njene strukture in posameznikov, ki jo sestavljajo. SV mora 
biti pripravljena tako na vojaške grožnje nacionalnemu ozemlju kot na naravne in druge nesreče ter na kibernetske grožnje in delovanje na kriznih območjih po svetu. Ni je organizacije, ki bi se bila sposobna odzivati na vse te grožnje hkrati, in tudi vojska ne bo v vseh primerih prevzemala vodilne vloge. So pa grožnje, pri katerih je treba prevzemati pobudo. To so tradicionalne vojaške grožnje nacionalnemu ozemlju in sodelovanje v mednarodnih operacijah in na misijah. Povsod drugod bo Slovenska vojska sodelovala, ponekod pretežno z moštvom in tehniko, na primer ZiR, drugje s posameznimi specializiranimi elementi, kot je kibernetska obramba, ali specializiranimi posamezniki, na primer v boju proti terorizmu.

Ključ je fleksibilnost, ki mora biti vgrajena v sistem in del vsakega posameznika v sistemu.

\section{OBSEG SLOVENSKE VOJSKE}

Izbira vojaške doktrine posamezne države v okviru tako imenovane velike državne strategije je odvisna od tega, kakšni naj bi bili karakter, obseg in struktura njenih oboroženih sil. Posen razlikuje med ofenzivnimi, defenzivnimi in odvračalnimi vojaškimi doktrinami. Cilj ofenzivnih doktrin je razorožitev nasprotnika oziroma uničenje njegovih oboroženih sil, cilj defenzivnih doktrin pa je, da se nasprotniku prepreči doseganje zastavljenih ciljev. Odvračalne doktrine imajo kot cilj kaznovanje nasprotnika, in sicer tako, da povečujejo njegove stroške (materialne, kadrovske in finančne), ne da bi pri tem zmanjševale svoje vire (Posen, 1984, str. 14).

Vojaška doktrina SV je, glede na veljavne strateške dokumente in veljavno vojaško doktrino, odvračalna. V vojaški doktrini piše, da je »Poslanstvo $S V$... odvrniti vojaško agresijo ...« (Furlan, 2006, str. 24). SV bi torej s svojim značajem, strukturo in obsegom morala služiti predvsem odvračanju morebitne nevarnosti. Seveda na SV in vojaško varnost Republike Slovenije ne moremo gledati ločeno od zavezništva. Dejstvo je, da članstvo v zavezništvu deluje odvračalno vsaj do konvencionalnih agresorjev. Se pa v delovanju zavezništva še vedno kaže kriza identitete (Grizold, 2005, str. 92, 93), ki je nastala ne le s koncem hladne vojne, temveč predvsem s spremenjeno percepcijo tega, kaj koncept varnosti po 11. septembru v resnici pomeni. Zavezništvo se po vrhu v Walesu jasneje zaveda, da se mora odločneje spopasti z novimi oblikami groženj ${ }^{8}$, in se je zavezalo, da bo odločneje pristopilo k razvoju zmogljivosti za spoprijemanje z njimi (Declaration, 2014, t. 64). Zavezništvo ima med svojimi temeljnimi nalogami navedeno odvračanje in obrambo pred grožnjo z agresijo kateri koli članici, a hkrati ugotavlja, da je konvencionalna agresija velikih razsežnosti proti zaveznicam malo verjetna, se je pa na daljši rokne da odpisati (NATO, AJP-01(D), str. 2-2 in 2-3). Doktrinarni dokumenti ugotavljajo, da so verjetnejše operacije odzivanja na krizne situacije ter transnacionalne in hibridne nasprotnike.

\footnotetext{
8 Zavezništvo govori o transnacionalnih in multidimenzionalnih grožnjah, o hibridnih grožnjah, terorizmu in nevarnosti, ki jo pomenijo balistični izstrelki (Declaration, 2014, t. 13, t. 32, t. 55). Tem grožnjam je skupno to, da za tarče nimajo le vojaških ciljev, temveč predvsem politične. Tako hibridne grožnje obsegajo mešanico odkritih in prikritih vojaških, paravojaških in civilnih groženj, skladno s trenutno situacijo.
} 
Tako je zavezništvo tudi strukturirano in v tej smeri bo potekalo njegovo nadaljnje preoblikovanje (Declaration, 2014, t. 64), taka pa bodo tudi pričakovanja do vseh članic. Skladno s Posnovimi definicijami vojaške doktrine menim, da je doktrina zavezništva ofenzivna, saj predvideva kratke in bliskovite spopade na ozemlju, ki ni domače, in daje velik poudarek silam, ki so visoko odzivne in strateško premestljive.

Temu sledi tudi SV, katere trenutni mirnodobni obseg in struktura sledita usmeritvam zavezništva, razen vojaške strateške rezerve9. Nikakor pa ne zadošča odvračanju morebitnih nasprotnikov z lastnimi oboroženimi silami, pri čemer bi morebitnemu nasprotniku lahko povzročali toliko izgub in tako dolgo, da oborožena agresija zanj ne bi bila smiselna. Tudi doktrina VSR RS navaja, da »morajo biti možne koristi potencialnega agresorja bistveno manjše od škode, ki mu jo lahko ... povzročimo kot morebitna žrtev napada« (MO RS, 2012, str. 6). Zavezništvo je v tem trenutku edini odvračalni element obrambne doktrine RS, SV pa v zdajšnji obliki ni primerna za doktrino odvračanja. Za Republiko Slovenijo in SV je odvračalna doktrina edina smiselna, saj majhne države z zelo omejenimi viri nimajo pogojev, da bi razvile ofenzivne ali defenzivne doktrine. Hkrati Republika Slovenija nima druge možnosti, kot da svojo varnost zagotavlja znotraj zavezništva. Druga možnost je še nevtralnost, vendar bi morala za to pridobiti ustrezna varnostna zagotovila $\mathrm{v}$ mednarodni skupnosti, ki pa je dolgoročno nepredvidljiva in anarhična. Za kaj takega Slovenija nima realnih možnosti in tveganje, ki bi se mu ob tem izpostavila, je nesprejemljivo.

Trenutni koncept strateške rezerve SV predvideva povečanje njenega obsega do 25.000 pripadnikov v enem letu (Doktrina VSR RS, 2012, str. 10, 24). Menim, da je to nerealno, saj SV nima več nobene rezerve, razen pogodbene rezerve (v nadaljevanju PPRS), ki pa ni namenjena rasti vojaške strateške rezerve, temveč zapolnitvi aktivne sestave SV. Uprave za obrambo sicer vpisujejo v vojaško evidenco, vendar vpisani državljani ne prejmejo obvestila o vojaškem usposabljanju, niti se ne spremlja njihova sposobnost za opravljanje vojaške službe. SV tudi nima načrtov, kako te evidence uporabiti in kaj storiti, če pride do tega, da jih bo treba uporabiti. Ob upoštevanju tempa sodobnega vojskovanja in razvijanja kriznih situacij SV ne bo imela leto dni časa, da se pripravi na morebitno grožnjo. Prav tako se ne ve, kako bi politika sprejela tako radikalno odločitev, kot je mobilizacija vojaške strateške rezerve leto dni vnaprej, ob tem, da ni nikakršnega zagotovila, da bo neka kriza oziroma vojna prerasla v spopad takih razsežnosti, ki bi ogrožal tudi Slovenijo. SV prav tako nima dovolj vodij, ki bi lahko usposobili 25.000 pripadnikov. Od kje bi namreč prišel kader, ki bi v enem letu usposobil vodje za strateško rezervo. Zavedati se je treba, da bi se velik del SV, predvsem njen najbolj usposobljeni del, ukvarjal z izvajanjem operativnih nalog, ki bi jih bilo v krizi gotovo veliko (med drugimi tudi izpolnjevanje obvez do zavezništva). Drugorazredni kader pa lahko usposobi kvečjemu tretjerazredni starešinski kader strateške rezerve. Morebitno usposabljanje v razmerah okupacij bi bilo tudi izjemno oteženo, predvsem pa počasno.

Koncept vojaške strateške rezerve (VSR) je le formalen, zapisan na papirju, in ni natančno razdelan niti preizkušen, zato ne more in ne bo zaživel. 
Načrti za povečevanje obsega SV, ki so znani samo v obliki koncepta, ne bodo delovali. Če resno razmišljamo o povečevanju obsega SV s strateško rezervo, moramo imeti vzpostavljen sistem, ki bo živel in bo vsaj deloma periodično preizkušen.

Slovenska vojska ima trenutno 8319 pripadnikov, od teh je 7169 pripadnikov stalne sestave (v nadaljevanju StaS), preostalih 1150 pa je pripadnikov PPRS. Številke veljajo za december 2014 (http:// www.slovenskavojska.si/o-slovenski-vojski/). Skupni dovoljeni obseg SV je do 10.000 pripadnikov, vendar SV tega ne dosega zaradi vladnih kadrovskih omejitev in tudi zaradi razmer na trgu delovne sile in lastne nekonkurenčnosti. Največja dovoljena številka za stalno sestavo je 7600 pripadnikov in 1500 pripadnikov za PPRS, skupaj torej 9100 pripadnikov.

Manevrski del SV, torej del, ki je namenjen temu, da se spoprime z nasprotnikom na bojišču in ga premaga v oboroženem boju, obsega štiri pehotne polke s 700 pripadniki po formaciji, skupaj torej približno 2800 pripadnikov ${ }^{10}$. Preostali predstavljajo bojno podporo, zagotovitev delovanja in poveljevanje in kontrolo (PINK) ter vojaško izobraževanje in usposabljanje. Ameriški general Georg C. Marshall je v intervjuju leta 1956 izjavil, da »je čisto napačna predpostavka, da je pehoto lahko izuriti« (Bolger, 1999, str. 29). Bližinski boj z nasprotnikom je za pehotnega vojaka izjemno osebno in stresno početje. Manj kot ima družba teh vojakov, boljši morajo biti. Dobra pehota je posebej izbrana, dobro usposobljena in predvsem sposobna sprejemati hitre odločitve in dobre presoje v boju (Bolger, 1999, str. 31).

To bi morala biti najpomembnejša kakovostna razlika med naborniško in poklicno pehoto. Naborniki opravljajo svoje naloge, ker jih morajo, poklicni vojaki pa načeloma to želijo delati. Če naborniška vojska natančno sledi programom, ki imajo vsebine predpisane s številom ur, mora poklicna vojska slediti doseganju standardov. Njihovo urjenje je in mora biti težje, realnejše in boljše.

Ena izmed prednosti naborniške vojske je številčnost. Vendar kakovost ne more vedno nadomestiti količine. Ob tem se nam zastavi vprašanje, kolikšna je ta številka za SV.

Kot navaja Doktrina VSR RS, se je vsaj od časa turških vpadov do osamosvojitve samoobrambna sposobnost prebivalstva na Slovenskem večkrat potrdila kot koristna. Kratek zgodovinski pregled oboroženih sil Slovenskega naroda v zadnjih 100 letih nam pokaže:

1. Vojska generala Maistra, leta 1918, približno 12.000 pripadnikov (http://www. slovenskavojska.si/o-slovenski-vojski/zgodovina/).

2. Slovenska narodnoosvobodilna vojska in partizanski odredi (SNOV in PO), avgust 1944, približno 21.700 pripadnikov (http://www.slovenskavojska.si/oslovenski-vojski/zgodovina/), do konca vojne naj bi to število naraslo na okoli 35.000 (Guštin v Bebler, 2005, str. 59-95).

\footnotetext{
${ }^{10}$ Gre za spletne vire, ki se nikjer ne sklicujejo na uradne vire in jih zato ne navajam posebej. Žal vsi meni znani uradni viri, povezani s številčnim obsegom enot SV, nosijo oznako zaupnosti in jih zato na tem mestu ne morem navesti. Za potrebe članka sklepam, da so dostopni spletni viri vsaj približno točni.
} 
3. Slovensko domobranstvo (SD), približno 13.500 (ibid).

4. Mobilizirani v nemško vojsko, 1941-1945, približno $50.000{ }^{11}$.

5. Teritorialna obramba RS, junij 1991, približno 35.000 pripadnikov (http://www. slovenskavojska.si/o-slovenski-vojski/zgodovina/).

Ob tem je treba upoštevati, da je vojska generala Maistra delovala skoraj izključno V severnem in SV delu Slovenije, torej na nekaj manj kot polovici današnjega slovenskega ozemlja.

Slovensko domobranstvo ${ }^{12}$ je bilo omejeno na tako imenovano Ljubljansko pokrajino oziroma operacijsko cono Jadransko Primorje, torej spet na nekaj manj kot polovico slovenskega ozemlja. Šele slovenska narodnoosvobodilna vojska in partizanski odredi so delovali na praktično celotnem ozemlju Slovenije, pri čemer pa je v njihovem primeru treba razumeti, da je šlo za gverilsko vojsko. ${ }^{13} \mathrm{SNOV}$ in PO so bili organizirani v dva korpusa in eno operativno cono, vendar sta številčnost in tudi bojna moč partizanskega korpusa bolj ustrezali enakovredni zavezniški pehotni diviziji. To lahko vidimo, če primerjamo številčnost in strukturo 7. korpusa SNOV in 2. pehotne divizije ZDA. ${ }^{14}$ Hkrati je treba vedeti, da sta tako slovensko domobranstvo kot slovenska narodnoosvobodilna vojska zajemala svoje pripadnike iz istega kadrovskega bazena slovenskega naroda med letoma 1941 in 1945, kamor pa je očitno zelo učinkovito in organizirano posegala tudi nemška vojska.

TO je leta 1991 s svojo prostorsko strukturo uspešno pokrila celotno slovensko ozemlje in uspešno onemogočala $\mathrm{v}$ doktrini manevrsko naravnanega nasprotnika, ni pa bila namenjena manevrskemu bojevanju pri obrambi teritorija. Njen končni obseg je bil junija 1991 približno 35.000 pripadnikov. Temu je treba prišteti še približno 10.000 miličnikov.

Zgodovinsko gledano torej lahko govorimo o 35.000 pripadnikih oboroženih formacij kot o tisti sili, ki lahko učinkovito onemogoča nasprotnikove sile na ozemlju velikosti Republike Slovenije. Prav sposobnost onemogočanja oziroma oviranja je tisto, kar dela vojaško doktrino države odvračalno, saj tako nasprotniku preprečujemo, da bi uresničil svoje cilje, in povečujemo njegove stroške (materialne, kadrovske in finančne) (Posen, 1984, str. 14). To potrjuje predpostavke iz ReSDPRO (do 10.000) in Doktrine vojaške strateške rezerve (do 25.000), ki skupaj predstavljata oboroženo silo 35.000 pripadnikov.

" Podatki o tem, koliko ljudi je bilo mobiliziranih v nemško vojsko, se zelo razlikujejo glede na vir. Seničar v svojem diplomskem delu navaja številko 28.000 do leta 1943 samo za Štajersko, hkrati pa navaja kot končno številko 150.000, kar vključuje vse, ki so bili mobilizirani v vojaške in paravojaške formacije okupatorja. Moja ocena je torej približna in se nanaša samo na mobilizirane v nemško vojsko.

12 V prispevku uporabljam oznako slovensko domobranstvo kot splošen naziv za enote, ki so sodelovale z okupatorjem, saj so se njihovi nazivi in organiziranost med vojnimi leti precej spreminjali.

${ }^{13}$ Brigade SNOV so bile enote, namenjene manevrskemu bojevanju. Preostanek SNOV so bile tako imenovane prostorske sile.

${ }_{14}$ Partizanske čete so štele od 30 do 80 borcev, bataljoni od 100 do 250 in brigade od 300 do 800 borcev (Guštin $v$ Bebler, 2005, str. 59-95). Enote SNOV bi lahko kljub temu samo številčno primerjali z zavezniškimi enotami eno raven nižje, nikakor pa ne tudi po ognjeni moči, po kateri so bile enote SNOV še šibkejše. 
Ob tem je razmerje med stalno sestavo in predvidenim številom vojne sestave oziroma tako imenovano strateško rezervo bistveno. Za ilustracijo lahko pogledamo nemško vojsko, ki je bila po prvi svetovni vojni omejena na številko 100.000, kar ni ustrezalo obrambnim potrebam Nemčije, če bi se ponovila vojna v Evropi. S tem namenom si je nemški generalštab prizadeval čim hitreje povečati obseg. Tako so ustvarili vojsko vodij s konceptom poveljevanja, pri čemer se je skoraj od vseh pripadnikov vojske pričakovalo, da bodo lahko prevzeli poveljniške dolžnosti do dve ravni višje, kot so ga v resnici opravljali v strukturi 100.000 pripadnikov. To jim je, ko so bile razmere za to primerne, omogočilo hitro rast, ne da bi se pri tem poslabšala kakovost. Tako se je po letu 1935 število zelo hitro povečalo s 100.000 najprej na 300.000 in nato na 1.000.000 leta 1938. Težava je bila, da temu industrija ni bila sposobna slediti in da je politično vodstvo zahtevalo še hitrejšo rast, in sicer 4.000.000 leta 1939. To je nato privedlo do poslabšanja kakovosti oboroženih sil (Craig, 1964). Ta zgodovinska izkušnja kaže, da je hitro povečanje oboroženih sil sicer mogoče, a morajo biti za to izpolnjeni nekateri pogoji, kot so vgrajen presežek usposobljenih vodij, pripravljena infrastruktura in zagotovljena materialna baza. Po drugi strani pa ima hitra rast kljub izpolnjevanju vseh pogojev tudi svoje omejitve, ki se kažejo predvsem v rasti, ki bi bila večja od trikratne.

Če bi SV morala vzpostaviti vojni obseg okrog 35.000 pripadnikov, kar kažejo zgodovinske izkušnje in strateški dokumenti, njena stalna sestava ne sme biti manjša od 10.000, pri čemer pa mora izpolnjevati tudi vse prej navedene pogoje. Najpomembnejše pri tem je, da ima ustrezno število usposobljenih vodij za prevzemanje dolžnosti v vojaški strateški rezervi.

\section{KARAKTER SLOVENSKE VOJSKE}

Slovenska vojska je z zadnjo transformacijo dobila novo strukturo, ki kaže pretežno pehotno organizacijo. Bojna moč SV temelji na štirih pehotnih polkih, ki imajo znotraj brigad na voljo še več bojnih »multiplikatorjev $\aleph^{15}$. Z njihovo pomočjo je vsaka izmed pehotnih brigad, vsaj v teoriji, sposobna oblikovati bataljonsko bojno skupino za potrebe zavezništva. Kakršna koli že je ali bo struktura SV v prihodnje, je dejstvo, da njena bojna moč temelji na pehotnih enotah ranga bataljona oziroma brigade. Vprašanje pa je, kakšno vrsto pehote naj bi te enote imele.

Zavezništvo pozna več različnih tipov pehote, od mehanizirane, motorizirane, mornariške, zračnodesantne, zračnopremične do gorske. Doktrinarno pojma lahka pehota zavezništvo ne pozna. Poznajo pa posamezne države zavezništva še druge specializirane tipe, kot so na primer ameriški rangerji, ki jih lahko obravnavamo kot lahko pehoto.

Če prepoznamo pehoto kot temelj bojne moči SV, se moramo vprašati tudi, kakšen tip pehote bi ustrezal obrambnim potrebam Republike Slovenije. V preteklosti so se

\footnotetext{
${ }_{15}$ To so enote bojne podpore, ki so v teoriji sicer res na voljo polkom, vendar o tem, kaj, če sploh kaj, dobijo polki, odloča izključno njihov poveljnik.
} 
pojavljale različne zamisli, od zračnodesantne pehote do zračnopremične in ranger bataljonov. Ideje so sicer zanimive in za marsikoga zelo privlačne, vendar menim, da se moramo najprej vprašati, čemu je posamezen tip pehote sploh namenjen, kakšne so njegove odlike in pomanjkljivosti ter kako se SV namerava bojevati z nasprotnikom ${ }^{16}$.

Naloge SV so zelo široke, od zaščite in reševanja do obrambe pred zunanjim napadalcem. Ni tipa pehote, ki bi idealno ustrezal vsem tem nalogam, menim pa, da moramo izhajati iz najbolj zahtevne naloge, torej izvajanja vojaške obrambe, in nato ugotoviti, kako to pehoto uporabiti tudi za druge naloge.

Zračnodesantna pehota: ima zelo specifično vlogo strateške projekcije vojaške sile ${ }^{17}$ na razdaljah, ki so zunaj dosega običajnih transportnih sredstev (prim. Granada). Kot taka je najboljša, ko skoči neposredno na nasprotnika, saj je najboljša prav v elementu presenečenja. Ko pa enkrat opravi z nasprotnikom na cilju, je zelo ranljiva (prim. Arnhem v drugi svetovni vojni). Primanjkuje ji mobilnosti (razen strateške), poleg tega pa je vzdrževanje ustrezne pripravljenosti teh enot zelo drago.

Zračnopremična pehota: je najbolj mobilna med vsemi tipi pehote (CC\&CS, 2011, str. A-104). Tako kot zračnodesantna pehota tudi zračnopremična zahteva specializirano urjenje, kajti ne gre le za to, da bi katero koli pehoto vkrcali v helikopterje in jo na določeni točki odložili. Njena moč je v sodelovanju pehote $\mathrm{z}$ letalstvom, a je hkrati to tudi njena največja ranljivost. Helikopterji niso oklepniki in ni treba veliko, da jih sestrelijo. ${ }^{18}$ Padec helikopterja pa je navadno usoden tako za posadko kot potnike. Zračnopremična pehota je močna le, ko in če sodelujejo pehota, artilerija in letalstvo (bojni helikopterji in letala). Helikopterji, predvsem bojni, tudi precej stanejo, ne le nakup, temveč tudi vzdrževanje njihovih zmogljivosti.

Mehanizirana pehota: omogoča napredovanje tankom, kadar zaradi terena ali nasprotnika to ni izvedljivo. Mehanizirana pehota se izkrca le, kadar je to nujno, sicer pa taktične naloge rešuje s svojimi vozili, s katerimi prikuje nasprotnikovo pehoto in omogoči napredovanje svojim tankom. Tako se za mehanizirano pehoto v zavezništvu predpostavlja, da je opremljena z vozili z najmanj 20-milimetrskim topom. ${ }^{19}$ Le ta orožja se namreč lahko bojujejo skupaj s tankovskim topom. Iz tega izhaja, da je mehanizirana pehota smiselna, če obstajajo tudi tankovske zmogljivosti. Samo pri skupnem bojevanju, pri katerem imajo tanki vodilno vlogo, lahko prednosti mehanizirane pehote povsem izkoristimo. Ne smemo namreč pozabiti, da so izkrcni elementi mehanizirane pehote navadno zelo majhni, manjši od lahke,

\footnotetext{
${ }^{16}$ Menim, da sem v članku že pokazal, da je normativna vojaška doktrina RS odvračalna in da je za države, kot je Slovenija, tudi edina mogoča.

${ }_{17}$ CC \& CS, 2011, str. A-104, točka 1.1.

18 Njena poglavitna omejitev je zaščita lastnih sil (CC \& CS, 2011, str. A-104, točka 2.9).

${ }^{19}$ NATO BI-SC Agreed Capability Codes and Capability Statements iz leta 2011 sicer ne opredeljuje eksplicitne zahteve za najmanj 20-milimetrski top v mehanizirani pehoti, vendar pa ta izhaja iz zahteve, da je mehanizirana pehota »sposobna podpore oklepnih enot« (str. A-103, točka 2.10). Drugi ustrezni viri zavezništva imajo oznako zaupnosti in jih kot take $v$ tem prispevku ne morem uporabiti.
} 
zračnodesantne in zračnopremične pehote ter se tako hitro iztrošijo. Oklepne enote so sicer v manevru najbolj učinkovite in najhitrejše, toda bojujejo se lahko le kot del celote $\mathrm{v}$ združenem bojevanju rodov. Kdor torej gradi mehanizirano pehoto, mora imeti tudi vse druge elemente - ustrezne oklepne enote, artilerijo, ki to podpira, in prevlado v zraku. Mehanizirana pehota se lahko bojuje tudi samostojno, brez tankov, in je v tem lahko zelo učinkovita, vendar to ni njen glavni namen. Pri vsem tem pa tako tanki kot bojna vozila pehote tudi precej stanejo, ne le njihova nabava, temveč tudi vzdrževanje zmogljivosti.

Motorizirana pehota: njena glavna odlika je prilagodljivost (Bolger, 1999, str. 259). Odlična je na težje prehodnem terenu (gore, gozd, močvirja, urbana naselja), ponoči in v slabih vremenskih razmerah. Njena glavna pomanjkljivost je, da je v premiku oziroma manevru vezana na noge oziroma motorizirana transportna sredstva ${ }^{20}$. Nima zaščite oklepa, razen, če je opremljena z oklepnimi transporterji. Treba pa je razumeti, da so oklepni transporterji le to, torej transportna vozila. Motorizirana pehota se bojuje brez vozil in je omejena v ognjeni moči, mobilnosti in zaščiti (CC\&CS, 2011, str. A-103). Bremena tovrstnega bojevanja na vojaka so ogromna tako v fizičnem kot psihičnem smislu.

Mornariška pehota: je podobno kot zračnodesantna namenjena strateški projekciji sile. Ker je vezana na ladijski transport, je precej počasnejša, ima pa zato veliko več ognjene moči in daljšo samozadostnost (15 dni na kopnem, na morju v regiji 6 mesecev - taki so podatki za mornariško pehoto ZDA). Mornariška pehota ima na voljo še lastno ladijsko in zračno podporo (CC \& CS, 2011, str. A-91, A-92).

Gorska pehota: je pehota, ki je s svojo usposobljenostjo in opremo specifično prilagojena delovanju v gorskem oziroma arktičnem svetu (CC \&CS, 2011, str. A-103, A-104). V primerjavi z motorizirano pehoto se gorska pehota za svoj premik naslanja bolj na helikopterske kot motorizirane zmogljivosti. Bojevanje v gorskem in arktičnem svetu poleg bojevanja pomeni velik fizični napor, zato je ustrezna selekcija za gorsko pehoto nujna.

Ranger pehota: je sicer del kopenske vojske ZDA, toda ta tip visoko usposobljene pehote najdemo tudi $\mathrm{v}$ drugih oboroženih silah. Rangerji so pehota, zelo dobro usposobljena, vodena in opremljena, pa vendarle samo pehota. V vojski ZDA so ranger bataljoni specializirani za zavzemanje letališč in v tem ni boljših. V specialnih silah ZDA, s katerimi večinoma sodelujejo, pa imajo primarno dve nalogi: sile za hitro posredovanje oziroma tako imenovani QRF in sile za naskok oziroma tako imenovani »raid« (Bolger, 1999, str. 191). Rangerji na bataljonski ravni ne poznajo izvidnikov in minometov, ker niso namenjeni dolgotrajnejšim bojnim operacijam, temveč bliskovitim neposrednim akcijam (Bolger, 1999, str. 212). Rangerji so pehotna elita, ki od svojih mož pričakuje najboljše in ima temu ustrezen selekcijski sistem. Standardi izvedbe osnov so odlični, za kar pa imajo tudi ustrezne pogoje - dovolj streliva za urjenje in časa (neobremenjenost s stražarsko službo in garnizonskimi dolžnostmi).

${ }^{20}$ To so lahko tovornjaki, oklepni transporterji $(4 \times 4,6 \times 6,8 \times 8)$ ali v skrajnosti kakršna koli druga vozila. 
Neodvisno od tipa mora biti sodobna, poklicna in mala pehota odlična $\mathrm{v}$ treh temeljnih prvinah: v fizični pripravljenosti, strelski izurjenosti in taktiki malih enot (Bolger, 1999, str. 234).

Vojaška doktrina SV na deklarativni ravni je torej odvračalna. Kot pa smo ugotavljali že v uvodu, je SV kopenska vojska s pehoto kot njenim osrednjim elementom bojne moči. Kakšna pehota torej ustreza tej doktrini? Takoj lahko izključimo zračnodesantno in mornariško pehoto, saj sta to tipa pehote, ki sta namenjena predvsem strateški projekciji sile in ofenzivni doktrini. Kljub temu to ni vzrok, da posamezne zmogljivosti SV ne bi imele teh sposobnosti. Tu gre predvsem za specialne sile, ki zaradi narave svojega dela vsekakor potrebujejo zračnodesantne zmogljivosti. Poleg tega bi veljalo proučiti tudi formacijo različnih mornariških pehotnih formacij, v smislu dobrih lekcij na področju obsega, oborožitve in ognjene moči.

Prav tako odpade tako imenovana ranger pehota, saj je visoko specializirana in ni namenjena dolgotrajnejšim bojnim operacijam, ki jih predpostavlja odvračalna doktrina. Bi pa veljalo proučiti njihove selekcijske postopke v smislu dvigovanja »esprit de corps«.

Zračnopremična pehota je zelo mobilna, a je hkrati tudi zelo draga. Bojni in transportni helikopterji so zapleteni in zelo dragi oborožitveni sistemi. Toda brez enih in drugih prave zračnopremične pehote ni. Poleg tega so to sistemi, ki so izrazito ofenzivni in namenjeni globokim prodorom oziroma preskakovanju nasprotnika, ne pa kontroli ozemlja.

Slovenska vojska postopoma umika tankovske zmogljivosti iz uporabe. Do izteka življenjske dobe bo zadržala le zmogljivost ene tankovske čete. Vsi preostali tanki in bojna vozila pehote bodo umaknjeni v strateško rezervo (MORS-SOPR, 2012, str. 39), zato je težko razumljiv argument, da SV potrebuje mehanizirano bataljonsko bojno skupino zaradi lastnega razvoja. Brez tankovske zmogljivosti tudi zmogljivost mehanizirane pehote v SV nima smisla, razen v luči izpolnjevanja zavez do zavezništva. Zavezništvo ima tankovske zmogljivosti in potrebuje mehanizirane zmogljivosti v svoji podpori. SV tako sicer lahko razvija mehanizirano zmogljivost, da bi prek nje dosegala večjo povezljivost v zavezništvo, vendar menim, da bi to lahko dosegala tudi na druge, finančno manj obremenjujoče načine - tudi zmogljivosti motorizirane pehote morajo biti povezljive $\mathrm{v}$ zavezništvo, prek informacijske tehnologije, postopkov in procedur, oborožitvenih zmogljivosti in sistema PINK. Največja težava vsakršnega koalicijskega delovanja je vedno vprašanje PINK (Posen, 1984, str. 81).

Na prvi pogled se gorska pehota zdi idealna za potrebe RS in SV. Dejstvo pa je, da visokogorje pokriva le slabo četrtino slovenskega ozemlja. Preostanek predstavljajo sredogorje, gričevje in ravnina. SV ima tudi jasno izražene ambicije z vzpostavitvijo Natovega centra odličnosti v gorskem bojevanju. Toda gorska pehota je premalo prilagodljiva, da bi predstavljala osnovo bojne moči SV. 
Tako ostane še motorizirana pehota. Njena glavna odlika je prav velika prilagodljivost. Na prvi pogled se sicer zdi, da je motorizirana pehota hkrati tudi najcenejša. Morda je res cenejša od večine drugih tipov pehote, a še zdaleč ni poceni. Motorizirana vozila, pa naj bodo to tovornjaki ali oklepni transporterji, niso poceni sistemi. Poleg tega mora motorizirana pehota svoje omejitve v mobilnosti, ognjeni moči in zaščiti nekako nadomestiti. Potrebuje več protioklepnih sredstev, več lažjih minometov in drugega podpornega orožja, poleg tega pa mora biti tudi na področju PINK povezljiva v sisteme zavezništva. Je pa motorizirana pehota tudi zaradi svoje številčnosti in transportnih sredstev še najprimernejša za sodelovanje v sistemu ZiR, kar se je pokazalo tudi ob zadnjih velikih naravnih nesrečah v RS, ob žledu in poplavah.

Sklep Kratek zgodovinski pregled in strateški dokumenti kažejo, da bi morala SV imeti možnost večanja svojega obsega na okrog 35.000 pripadnikov. Hkrati s predlaganim maksimalnim obsegom SV odvračalna vojaška doktrina, širok zakonski nabor nalog in omejena finančna sredstva kažejo na to, da bi morali bojno jedro SV sestavljati motorizirana in lahka pehota.

Seveda bi bilo nesmiselno vzdrževati stalno sestavo v končnem obsegu 35.000, mora pa imeti SV vse sistemske nastavke, da bi lahko ob izraženi potrebi brez večjih naporov narasla do tega obsega. Doktrina VSR RS predvideva le sistemske nastavke, brez pripravljenih načrtov in z malo večinoma prostovoljno usposobljenega kadra. SV hkrati daje eno leto, da se njen obseg poveča za do 25.000 pripadnikov. Ob tem pa se pojavljajo zahteve po še dodatnem zmanjševanju trenutnega obsega SV. Menimo, da slednje ne morejo vzdržati trezne strokovne presoje, razen če ne spremenimo zakonsko opredeljenih nalog SV v smislu zavestne odpovedi učinkovitemu oboroženemu odporu v primeru ogrožanja nacionalne suverenosti. Hkrati menimo, da tudi konceptualne rešitve, ki jih predvideva Doktrina VSR RS, ne bodo vzdržale resnega preizkusa. SV in tudi preostanek obrambnega sistema RS V trenutnem stanju nikakor nista sposobna v enem letu iz trenutnega stanja vzpostaviti sistema, katerega končni rezultat bi bil 35.000 za boj usposobljenih pripadnikov, razporejenih v ustrezne formacije. Nemogoče je tudi pričakovati, da bi SV lahko v trenutnih finančnih in političnih razmerah kakor koli povečevala svoj mirnodobni obseg.

Rešitve bi se morale poiskati nekje vmes. SV bi morala imeti pripravljene načrte uporabe VSR in pripravljene formacije enot $\mathrm{VSR}^{21}$. To bi njej in preostanku obrambnega sistema omogočalo materialno in kadrovsko načrtovanje. To SV tudi praktično nič ne stane, razen delovnih ur štabnih častnikov in uradnikov MO RS, ki morajo te načrte in formacije pripraviti. ${ }^{22}$

\footnotetext{
${ }^{21}$ Skladno z ZoObr bi to predstavljalo vojno formacijo $S V$.

22 VSR bi morala obstajati kot vojna formacija, brez statusnih in plačilnih ugodnosti mirnodobnih formacij. Nanje ne sme biti mogoče predhodno postavljati pripadnikov StaS, ne, dokler ne pride do odločitve o aktiviranju VSR. Pripravljeni morajo biti načrti o popolnjevanju vojnih formacij s pripadniki StaS. V nasprotnem primeru se bo koncept izrodil, kot smo to v preteklosti že poznali in bi se VSR uporabljala za reševanje karier posameznikov. To pa bi bilo kontraproduktivno.
} 
V tem okviru je potreben tudi razmislek o strukturi in namenu PPRS. S PPRS bi lahko zagotovili del najpomembnejšega poveljniškega kadra za VSR.

Bistven je vojaški izobraževalni sistem, ki mora omogočiti trikratno rast mirnodobne strukture SV. To ne pomeni, da mora biti tako obsežen, temveč, da mora $\mathrm{z}$ izobraževanjem in usposabljanjem pripraviti poveljujoči kader mirnodobne sestave na prevzemanje višjih dolžnosti v VSR. ${ }^{23}$

Veljalo bi tudi razmisliti o tem, kako zagotoviti ustreznejše število usposobljenih posameznikov za VSR. Rast z 10.000 do 35.000 brez vnaprej pripravljenih jasno opredeljenih in preizkušenih načrtov ter formacij je nerealen. Nerealen je v 365 dneh, če bi jih bilo sploh toliko na voljo, o čemer pa ob sodobnem tempu razvoja kriznih situacij močno dvomim. Očitno je, da zanašanje na tiste, ki so prostovoljno odslužili vojaški rok, ne bo dovolj. Najlažja bi bila seveda ponovna uvedba neke oblike državljanske obveznosti, ki bi državljanom dala temeljno vojaško znanje, potrebno za hitro vzpostavitev VSR, mogoče v krajši obliki, kot smo jo poznali (do 3 mesece), in ki bi bila dopolnjena $\mathrm{z}$ vsebinami ZiR. ${ }^{24}$ Toda ker je to malo verjetno, bi morali razmisliti o drugih možnostih, kot je uvajanje obrambnih oziroma vojaških vsebin med obvezne vsebine v srednjih šolah in morda celo na fakultetah.

Ob tem mora SV zadržati vsaj trenutni, z ReSDPRO dovoljeni mirnodobni obseg do 10.000 pripadnikov. Vsako zmanjševanje pod ta obseg bo onemogočalo realnoizvedbo ideje o rasti VSR za do 25.000 pripadnikov. Preprosto bo to fizično neizvedljivo V času, ki bi bil lahko na voljo. Ob tem bo treba izvesti ukrepe za pridobivanje kadra za zapolnitev mest v StaS, kar pa bo s seboj nujno prineslo neželene finančne posledice. Varnost pač stane in v nasprotju s krilatico, da se z manj lahko naredi več, so meje, prek katerih je manj pač samo še manj.

Bojno jedro mirnodobne sestave SV bi torej morala sestavljati motorizirana pehota, bojno jedro vojne sestave (obseg 35.000) pa kombinacija motorizirane in lahke pehote (motorizirana v delu, ki bi izvajal manevrsko vojskovanje ${ }^{25}$, in lahka v delu, ki bi pokrival prostor ${ }^{26}$ ).

Motorizirana pehota je dovolj prilagodljiva, da bi lahko izpolnjevala vse zakonsko zastavljene naloge, hkrati pa bi bila finančno vzdržljiva. To, kar Slovenija prispeva v zavezništvo, je vedno stvar pogajanj in bi moralo v prvi vrsti odražati njeno

${ }^{23}$ Poveljniki vodov bi morali imeti znanje za vodenje čete VSR in delo na najpomembnejših štabnih dolžnostih VSR. Poveljniki čet bi morali vedeti, kako voditi bataljone, polke VSR itn.

${ }^{24}$ Taka oblika naborništva ne bi dala bojno uporabnih enot, bi pa zagotovila za ravnanje z orožjem usposobljene posameznike s temeljnim taktičnim znanjem na ravni oddelka, morda tudi voda. Hkrati bi omogočala državljanom aktivnejšo udeležbo v aktivnostih ZiR.

${ }^{25}$ Premestljive in nepremestljive sile v visoki in nizki stopnji pripravljenosti. Oblikovanje teh mora omogočati mirnodobna formacija, pri čemer StaS oblikuje premestljive sile za delovanje v okviru zavezništva (bataljonske bojne skupine in drugi cilji zmogljivosti Nata za SV), kombinacija StaS in PPRS pa omogoča oblikovanje sil za delovanje doma (dve brigadni bojni skupini).

${ }^{26}$ Nepremestljive sile z daljšim časom vzpostavitve pripravljenosti glede na Vojaško doktrino SV. Te sile bi predstavljala VSR. 
odvračalno vojaško doktrino. Izpolnjevanje zavez do zavezništva je pomembno in vpliva na kredibilnost države v mednarodnem okolju. Slovenija mora dati tudi sorazmerni prispevek k skupni varnosti, ki jo zavezništvo daje. Prevečkrat se $\mathrm{v}$ javnosti pojavljajo samo negativne strani članstva $\mathrm{v}$ zavezništvu, hkrati pa se pozablja, da na primer Republika Slovenija z instrumenti zavezništva brez velikih stroškov varuje svoj zračni prostor, uporablja vadišča in strelišča zavezništva, kakršnih sama nima, itn.

Sodobna motorizirana pehota ni poceni sistem. Morda ima kdo v mislih slabo opremljeno in nekakovostno izurjeno oboroženo silo, kar pa ne bi moglo biti dlje od resnice. Sodobna motorizirana pehota je dobro opremljena in dobro usposobljena vojaška sila, ki ima sicer omejitve v mobilnosti, ognjeni moči in zaščiti, a ima tudi sisteme, urjenje in poveljniški kader, ki lahko te pomanjkljivosti nevtralizirajo. Največja odlika motorizirane, pa tudi lahke pehote, je njena prilagodljivost.

Javnofinančna stvarnost je neusmiljena in ob predvidenih trendih virov za potrebe SV se moramo vprašati, kako naprej. Vztrajanje na številkah, ki jih finance ne dovoljujejo, je lahko samo kontraproduktivno. Minimum, pod katerega SV ne sme iti, je sledenje ciljem zmogljivosti, dogovorjenih z zavezništvom. Mogoče bi lahko katerega izmed ciljev zmogljivosti tudi spremenili skozi procese obrambnega načrtovanja zavezništva. Izpolnjevanje ciljev zmogljivosti hkrati z izpolnjevanjem obvez do zavezništva pomeni tudi zadrževanje minimalnega strokovnega znanja in vsaj okostja strukture SV. Ne omogoča pa izpolnjevanje vseh zakonsko določenih nalog SV in močno omejuje celo sodelovanje v sistemu ZiR. Cilji zmogljivosti številčno predstavljajo približno $4100^{27}$ pripadnikov StaS, vendar tudi ti sami zase ne morejo obstajati. Tudi zanje so potrebni zunanji elementi zagotovitve delovanja (vzdrževanje, oskrba, transport itn.), infrastrukture, izobraževanja in usposabljanja ter PINK (tudi PINK z zavezništvom). Ko bi prišteli to, kar je nujno za vzpostavitev CZ, bi verjetno prišli do približno 6500 pripadnikov StaS. A to je lahko le začasna rešitev, ki premošča slabo finančno stanje in v resnici verjetno ne prinaša toliko finančnih koristi, kot povzroča nacionalnovarnostne škode. Bi pa omogočila prenos dela finančnih sredstev iz postavke osebni prejemki pripadnikov na postavke modernizacije in tako zagnala razvoj $\mathrm{CZ}$.

Ob tem se je treba zavedati tudi, kakšna so priporočila zavezništva, povezana s premestljivostjo, visoko stopnjo pripravljenosti in vzdržljivost. Priporočila zavezništva so, da imajo oborožene sile 50 odstotkov premestljivih sil, 10 odstotkov $\mathrm{v}$ visoki stopnji pripravljenosti doma in 0,8 odstotka vzdržljivih. Glede na to, da vse zmogljivosti CZ spadajo med premestljive sile, bi glede na priporočila zavezništva končni obseg SV ne smel biti manjši od okoli 8200 pripadnikov.

\footnotetext{
${ }^{27}$ Gre za spletne vire, ki se nikjer ne sklicujejo na uradne vire in jih zato ne navajam posebej. Žal vsi meni znani uradni viri, povezani z obsegom CZ, nosijo oznako zaupnosti in jih zato ne morem navesti. Za potrebe članka sklepam, da so dostopni spletni viri vsaj približno točni.
} 
SV bi v vsakem primeru morala imeti pripravljene načrte in formacije za strukturo 10.000 StaS ter politična zagotovila za načrte rasti in popolnjevanja formacij, takoj ko bi javnofinančni položaj to dovoljeval.

$\mathrm{Ob}$ tem se mora postaviti jasna prioriteta popolnjenosti enot, ki uresničujejo $\mathrm{CZ}$ in izpolnjujejo zaveze do zavezništva. Preostanek StaS je namenjen najprej vzpostavitvi dveh manevrskih brigad lahke pehote $\mathrm{z}$ vsemi potrebnimi bojnimi multiplikatorji in nato vzpostavitvi VSR v primeru njenega aktiviranja.

SV mora torej odločno in argumentirano nastopiti proti vsakršnim poskusom zmanjševanja njenega trenutnega obsega, hkrati pa aktivno spodbujati javno razpravo o njenem namenu, obsegu, značaju in strukturi. Za potrebe te razprave se mora tudi notranje poenotiti in pripraviti strokovno utemeljene argumente, ki jih bo zagovarjala. Končni rezultat še vedno utegne biti za SV negativen in v tem primeru bomo njeni pripadniki morali tudi tovrstne končne odločitve sprejeti in iz njih iztisniti največ, kar se bo dalo. Ne smemo pa dopustiti, da bi se kakršne koli odločitve o zmanjšanju obsega sprejemale brez jasno slišanih in sprejetih argumentov SV.

\section{Literatura}

1. Bebler, A., 2005. Sodobno vojaštvo in družba. Ljubljana: FDV.

2. Bolger, D. P., 1999. Death Ground - Today's American Infantry in Battle. Random House Publishiing Group.

3. Craig, G. A., 1964. The Politics of the Prussian Army 1640-1945. London: Oxford University Press.

4. Declaration Issued by the Heads of State and Government participating in the meeting of the North Atlantic Council in Wales, Press Release (2014) 120, Issued on 05 Sep. 2014 Last updated: 16.92014.

5. Državni zbor RS, 2010. Resolucija o strategiji nacionalne varnosti Republike Slovenije (ReSVN-1). Ljubljana: MORS.

6. Državni zbor RS, 2010. Resolucija o splošnem dolgoročnem programu razvoja in opremljanja Slovenske vojske do leta 2025 (ReSDPRO SV 2025). Ljubljana: MORS.

7. Furlan, B. (et al), 2006. Vojaška doktrina. Ljubljana: Defensor d.o.o.

8. Grizold, A. 2005. SLOVENIJA V SPREMENJENEM VARNOSTNEM OKOLJU, K razvoju obrambno zaščitnega sistema: Izzivi in spodbude. Ljubljana, FDV.

9. Kuster, J., 1979. Spominski zbornik ob 60-letnici bojev za severno slovensko mejo 19181919. Maribor: ZGEP Pomurski tisk.

10. Moscos, C.C., 2000. The Postmodern Military. New York: Oxford University Press.

11. MORS, 2012. Doktrina vojaške strateške rezerve RS. Ljubljana: MORS.

12. MORS, 2009. Strateški pregled obrambnega resorja 2009. Ljubljana: MORS.

13. NATO, 2010. AJP-01(D) Alied Joint Doctrine. NATO Stardandisation Agency.

14. NATO, 2011. Bi-Sc Agreed Capability Codes and Capability Statements. Belgium: Supreme Allied Commander, Europe.

15. Posen, B. R., 1984. The Sources of military doctrine-France, Britain, and Germany Between the World Wars. Beograd 1992: Vojnoizdavački i Novinski centar.

16. Seničar, M., 2006. Slovenski fantje v vojski tretjega rajha-diplomsko delo. Ljubljana: FDV.

17. Severnoatlantska pogodba na http://nato.gov.si/slo/dokumenti/severnoatlantska-pogodba, 13. 1. 2015. 
18. The North Atlantic Treaty na http://www.nato.int/nato_static/assets/pdf/stock publications/20120822_nato_treaty_en_light_2009.pdjf, 13. 1. 2015.

19. The Wales Declaration on the Transatlantic Bond, Press Release (2014) 122, Issued on 05 Sep. 2014, 10. 9. 2014.

20. Vlada RS, 2012. Obrambna strategija Republike Slovenije. Ljubljana: št. 80000-1/2012/4, 7. 12.2012.

21. Vlada RS, 2013. Srednjeročni obrambni program Republike Slovenije 2013-2018. Ljubljana: št. 80300-1/2013/3 z dne 1. 2. 2013. http://youtu.be/tEHYGFWO7pQ http:// www.slovenskavojska.si/o-slovenski-vojski/.

22. Vlada RS, 2004. Zakon o obrambi (uradno prečiščeno besedilo). Ljubljana: ULRS.

23. O Slovenski vojski, http://www.slovenskavojska.si/o-slovenski-vojski/zgodovina, 13. 1. 2015.

24. http://youtu.be/tEHYGFWO7pQ, 13. 1. 2015. 